\title{
Nonresectional folding repair techniques for posterior leaflet lesions in degenerative mitral regurgitation
}

Minoru Tabata, MD, PhD, MPH, ${ }^{\mathrm{a}, \mathrm{b}}$ and Hiromi Yanagisawa, $\mathrm{MD}^{\mathrm{a}}$

Surgical mitral valve repair is a gold standard treatment for severe degenerative mitral regurgitation (MR). Leaflet prolapse, excess leaflet width, excess leaflet height, annular geometry, or a combination of these factors must be corrected during degenerative MR repair. The standard approaches for excess leaflet tissue are resectional repair techniques, such as triangular/quadrangular resection and sliding valvuloplasty, and those for leaflet prolapse are leaflet resection and chordal replacement. For posterior leaflet lesions, nonresectional folding approaches are alternatives to those.

Nonresectional folding techniques are advantageous because of their simplicity and reversibility. Surgeons can undo the folding simply by cutting the folding sutures if they are unsatisfied with the repaired valve, whereas a resected leaflet cannot be undone. These options help surgeons handle different degenerative MR lesions in various situations. However, nonresectional folding techniques are limited by anatomy, and the long-term results are unknown. Therefore, surgeons should understand the limitations of nonresectional folding approaches and carefully select suitable cases.

This article reviewed several different nonresectional folding techniques and included our original data of nonresectional folding repair cases that were approved by the Institutional Review Board of Tokyo Bay Urayasu Ichikawa Medical Center (Institutional Review Board \#2021-694).

\section{SURGICAL TECHNIQUES \\ Leaflet Folding in a Vertical Direction}

The concept of vertical folding of the posterior leaflet was developed by $\mathrm{McGoon}{ }^{1}$ more than half a century ago but has been unpopular and used less than leaflet resection techniques for many years. However, it has recently received more attention, simultaneously with minimally

\footnotetext{
From the ${ }^{a}$ Department of Cardiovascular Surgery, Tokyo Bay Urayasu Ichikawa Medical Center, Chiba, Japan; and ${ }^{\mathrm{b}}$ Department of Cardiovascular Surgery, Toranomon Hospital, Tokyo, Japan.

Received for publication July 31, 2021; accepted for publication Sept 27, 2021; available ahead of print Oct 2, 2021.

Address for reprints: Minoru Tabata, MD, PhD, MPH, Department of Cardiovascular Surgery, Tokyo Bay Urayasu Ichikawa Medical Center, 3-4-32 Todaijima, Urayasu-shi, Chiba 279-0001, Japan (E-mail: mtabata@post.harvard.edu). JTCVS Techniques 2021;10:68-73

2666-2507

Copyright (C) 2021 The Author(s). Published by Elsevier Inc. on behalf of The American Association for Thoracic Surgery. This is an open access article under the CC BY-NC-ND license (http://creativecommons.org/licenses/by-nc-nd/4.0/).

https://doi.org/10.1016/j.xjtc.2021.09.052
}
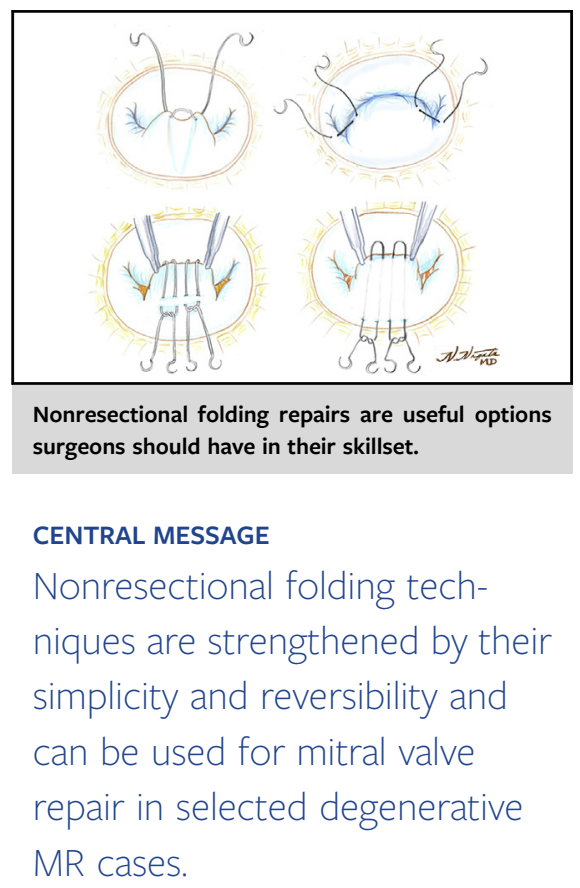

See Commentary on page 74 .

invasive approaches. ${ }^{2,3}$ In this folding technique, the prolapsed leaflet segment is plicated using interrupted or running sutures (Figure 1). Some surgeons use this technique to determine how much leaflet to resect before actual leaflet resection. This technique does not reduce the leaflet height or prevent systolic anterior motion (SAM) after repairing a tall posterior leaflet, and additional procedures such as neochordal replacement and anchoring of the folded posterior leaflet to the posterior ventricular wall ${ }^{4}$ may be necessary to manage excess leaflet height.

\section{Leaflet Folding at the Indentation}

Indentation closure is a classic mitral valve repair technique and has been used for the purpose of gap closure after leaflet resection. ${ }^{5,6}$ In addition, it can be used for the correction of prolapse and excess leaflet width. ${ }^{7}$ The prolapsed segment near the indentation can be supported by the normal chordae of the neighboring scallop by suturing the indentation. The excess leaflet can be folded into the ventricle by suturing the indentation with big suture bites (Figure 2). This technique is rarely used as a primary procedure and is often only 


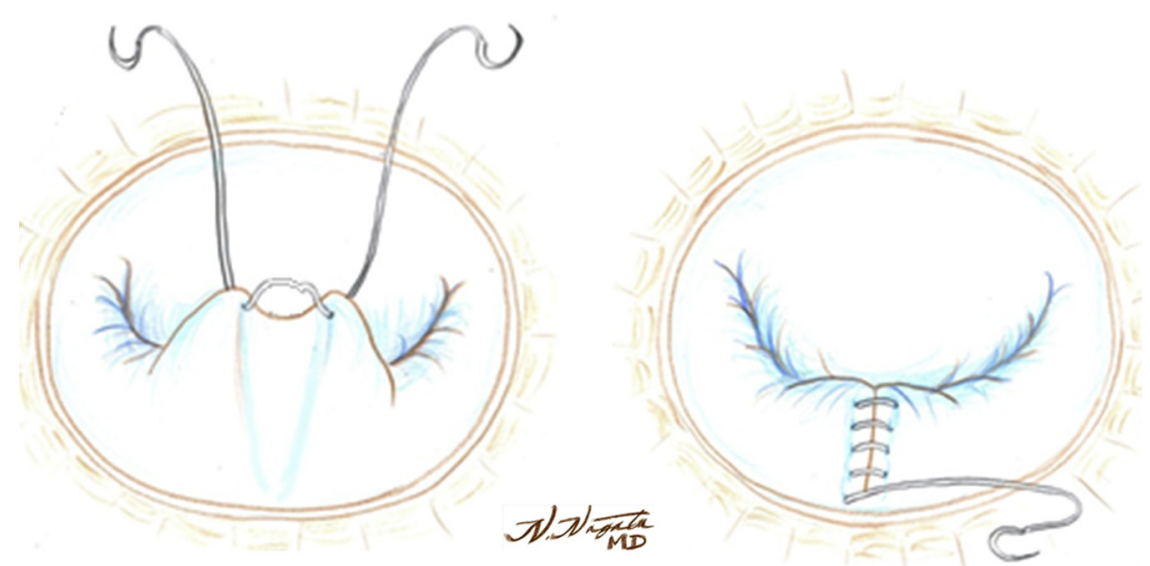

FIGURE 1. Vertical folding of the posterior leaflet. Left: The edges of the prolapsed segment are passed with a suture. Right: The prolapsed segment is plicated with a running suture.

used as an adjunctive procedure with other techniques such as neochordal replacement. ${ }^{7}$

\section{Leaflet Folding Using the Neochordae}

We previously introduced modified neochordal replacement (chordal foldoplasty) to repair both prolapse and excess leaflet height without leaflet resection. ${ }^{8}$ In this technique, applicable to any posterior leaflet scallop, neochordae are sutured on the middle portion of the P2 scallop instead of the leaflet edge (Figure 3). The neochordae naturally fold the leaflet toward the posterior ventricular wall, creating a new coaptation surface and blocking the leaflet tip from moving forward. ${ }^{8}$

It is difficult to determine the neochordal length with premeasurement techniques in chordal foldoplasty because the appropriate length varies by the location at which sutures are fixed on the leaflet. The length of neochordae is determined with the tourniquet technique in which we temporarily hold the neochodae at a specific length using small tourniquets, assessed the leaflet competency by injecting saline into the left ventricle, and adjust the length by sliding the tourniquets. ${ }^{9}$
In another leaflet folding technique using the neochordae, the 2 arms of each neochordae are passed through the free margin of the prolapsed leaflet and those sutures are weaved from the free margin up to the coaptation line with 2 or 3 full-thickness bites. ${ }^{10}$ In this technique, the neochordal length is determined on the basis of the principle of basal-marginal chordae equivalence. The leaflet is temporarily folded to approximate the coaptation line to the annulus, the length of the neochordae is set the same as the length of the basal chordae, and the leaflet is unfolded. ${ }^{10}$

\section{Leaflet Folding in a Horizontal Direction}

The horizontal folding repair technique is also simple and reversible. ${ }^{11-13}$ The prolapsed or redundant posterior leaflet segment is folded with mattress sutures passed from the leaflet edge to the annulus or midportion of the leaflet (Figure 4). This technique simultaneously corrects leaflet prolapse and reduces the posterior leaflet height. The leaflet height can be adjusted by changing the exit points of sutures, although it cannot be reduced to less than half.

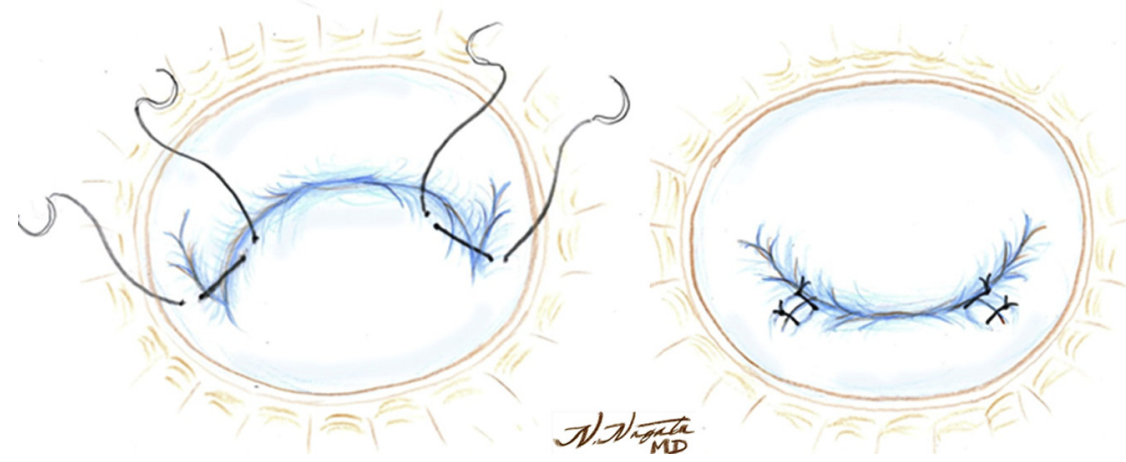

FIGURE 2. Folding of the posterior leaflet at the indentations. Left: The indentations are closed by taking big bites on the redundant segment. Right: The redundant segment is inverted into the left ventricle after indentation closure. 

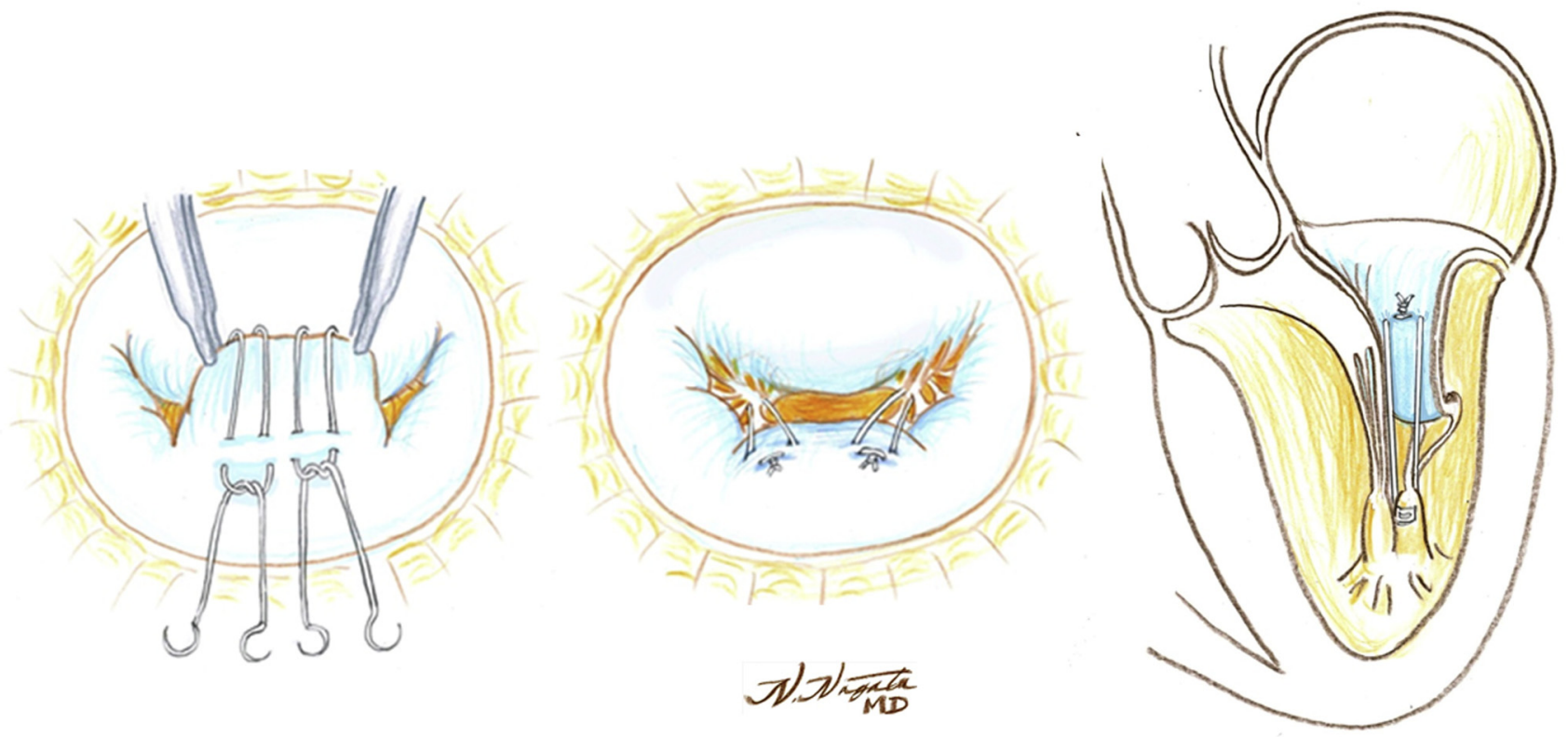

FIGURE 3. Chordal foldoplasty. Left: The neochordal sutures are passed onto the atrial surface of the midportion of the tall posterior leaflet in a mattress fashion. Center: Two pairs of neochordae are placed on the midportion of the posterior leaflet. Right: The posterior leaflet tip is naturally folded toward the posterior wall and blocked from moving forward by the neochordae.

\section{OUTCOMES}

The early folding repair technique outcomes have been excellent, although little has been reported on late outcomes. Woo and MacArthur $^{2}$ reported the early outcomes of 87 patients undergoing vertical folding mitral valve repair. Of those, $85 \%$ of patients had posterior leaflet prolapse, and $15 \%$ had bileaflet prolapse. A minimally invasive approach was used in $62 \%$ of patients, and there was no operative death or stroke. Predischarge echocardiography showed $0 / 1+$ MR and no SAM in all patients. There was no recurrent MR or reoperation of the mitral valve during a mean follow-up of 1 year. $^{2}$ Tsukui and colleagues ${ }^{3}$ also reported the early outcomes of 60 patients undergoing vertical folding repair. Predischarge echocardiography showed none or trivial MR in $80 \%$ and mild MR in $20 \%$ of patients, and no SAM. There was also no recurrent MR
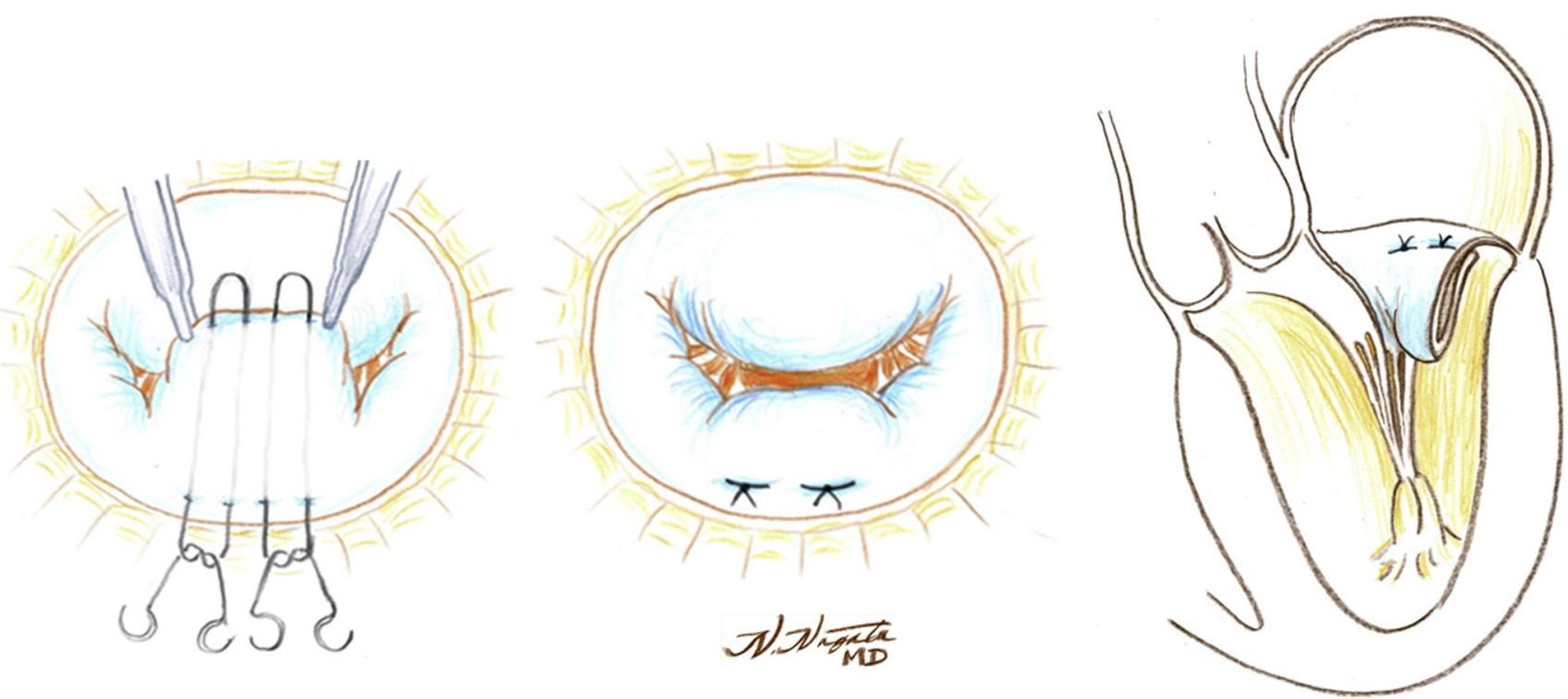

FIGURE 4. Horizontal folding of the posterior leaflet. Left: Mattress sutures are passed from the tip to the base of the posterior leaflet. Center and Right: The posterior leaflet is folded, reducing the leaflet height. 
or reoperation during a mean follow-up period of 17 months.

There have been few reports on indentation closure outcomes. We previously reported that 98 of 897 patients who underwent mitral valve repair for degenerative MR had indentation closure as an adjunctive procedure and reviewed their outcomes. ${ }^{7}$ Of those, $68 \%$ had posterior leaflet prolapse, $26 \%$ had bileaflet prolapse, and $6 \%$ had anterior leaflet prolapse. Indentation closure was performed for gap closure $(58 \%)$, prolapse repair $(11 \%)$, redundancy repair $(16 \%)$, and leaflet deficiency repair (12\%). Predischarge echocardiography showed no residual greater than mild MR in all patients and a mean transmitral pressure gradient of $5 \mathrm{~mm} \mathrm{Hg}$ or greater in $16 \%$ of patients. Further, multivariable analysis showed that small ring or band use, commissural plication, and edge-to-edge repair are significant predictors of a high-pressure gradient. There were 6 patients with recurrent moderate or severe MR during a mean follow-up of 44 months. ${ }^{7}$

Early outcomes of 8 initial cases of chordal foldoplasty were previously reported. ${ }^{8}$ We reviewed 60 patients who underwent chordal foldoplasty from August 2013 and May 2020. The median age of patients was 55 years (range, 30-85 years). All patients had severe degenerative MR, $77 \%$ had posterior leaflet prolapse, and $23 \%$ had bileaflet prolapse. A minimally invasive approach was used in $92 \%$ of patients. There was no operative death. Predischarge echocardiography showed none or trivial MR in $98 \%$ and mild MR in $2 \%$ of patients, and no SAM. The Kaplan-Meier analysis showed that the freedom rate from recurrent moderate or severe MR was $89.4 \%$ at 5 years. Two cases required mitral valve reoperation during a median follow-up of 27 months. In 1 reoperation case, 2 pairs of neochordae placed on the sclerotic and highly redundant P2 segment were fixed on the same papillary muscle head. At the time of the early redo surgery, 6 months after the first surgery, the neochordae were found to be entirely off the papillary muscle. Consequently, the mitral valve was rerepaired by sliding valvuloplasty. In the other reoperation case, the neochordae were found to move toward the papillary muscle tip, and the valve was re-repaired by triangular resection and neochordal replacement.

Fuster and colleagues ${ }^{10}$ reviewed their 68 cases of mitral valve repair in which they performed their chordal folding technique. In their series, $59 \%$ of patients had posterior leaflet prolapse, $19 \%$ had anterior leaflet prolapse, and $22 \%$ had bileaflet prolapse. No SAM was found on intraoperative transesophageal echocardiography. Predischarge or 1-month echocardiography was performed in 67 patients and showed that 51 patients had no MR and 16 patients had grade $1 \mathrm{MR}$. Six-month echocardiography that was performed in 63 patients showed zero/grade $1 \mathrm{MR}$ in 62 patients and grade $2 \mathrm{MR}$ in 1 patient. In the patient with grade $2 \mathrm{MR}$, the grade of MR did not change at 18-month follow-up. Two-year echocardiography that was performed in 41 patients showed zero/grade $1 \mathrm{MR}$ in all patients. ${ }^{10}$

Gosev and colleagues ${ }^{14}$ reported the long-term outcomes of horizontal folding repair, finding that 7 of 161 patients $(4.3 \%)$ had mitral valve reoperation during a mean follow-up period of 6.8 years. The echocardiographic follow-up details were not presented, but they reported that $2 \%$ of patients had moderate MR on the follow-up echocardiography. ${ }^{14}$

\section{DISCUSSION}

There has been some criticism that nonresectional folding approaches are overly simplified repair techniques used only to fit with minimally invasive surgery. However, the procedure simplicity reduces operation, cardiopulmonary bypass, and aortic crossclamping times and promotes mitral valve repair reproducibility, potentially improving operative outcomes. The reversibility of the procedure also allows surgeons to explore better solutions after examining the repaired valve. Thus, these advantages of nonresectional folding should be considered not only for minimally invasive surgery but also for conventional surgery via a median sternotomy unless they sacrifice the mitral valve repair success and durability.

Folding the leaflet in a vertical direction, so called "McGoon's plication technique," is a simple and reversible method to fix the excess leaflet width. This technique may not be feasible for a very thick leaflet because vertical folding of a thick leaflet puts too much tension on the sutures and the leaflet by elastic restoring force. This technique is a useful option for the wide posterior leaflet unless it is very thick. Because it does not reduce the leaflet height, it may be necessary to add other techniques such as neochordal replacement and anchoring of the plicated leaflet ${ }^{4}$ to prevent SAM.

Folding the leaflet at the indentation puts less tension on the leaflet and sutures than folding the midportion of the leaflet due to less elastic restoring force. Conversely, indentation closure can cause mitral stenosis by restricting the posterior leaflet opening. This technique should not be used in combination with commissural plication or annuloplasty with a small ring. ${ }^{7}$

Folding techniques using the neochordae provide deep leaflet coaptation and preserves excellent leaflet motion,, 10 which are advantages of neochordal techniques over resectional techniques. ${ }^{15,16}$ They are still simple, although they require determining the length of the neochordae. As described, the premeasurement methods are unsuitable, and intraoperative adjustment methods such as the tourniquet technique and the method based on the principle of basal-marginal chordae equivalence are useful for chordal folding repair techniques. ${ }^{9,10}$ Extensive shortening of the neochordae placed on the tip of the tall leaflet is also effective to deal with the risk of SAM. However, it might not 
prevent a tall posterior leaflet (eg, $>30 \mathrm{~mm}$ in the height) from pushing the anterior leaflet forward, or it could cause leaflet immorbility. ${ }^{10}$ These chordal folding techniques are effective even for a very tall posterior leaflet, and they preserve leaflet mobility. ${ }^{8} 10$ From our experience, we learned that each neochord of chordal foldoplasty should be fixed on different papillary muscle heads to distribute the systolic stress a large leaflet receives. These chordal folding techniques do not reduce the leaflet width. It may be necessary to add other repair techniques such as leaflet resection and other folding techniques when the leaflet is very wide.

Folding the leaflet in a horizontal direction is another simple repair technique. In many cases, however, the folded posterior leaflet becomes immobile, and the valve transforms to a unicuspid-like shape, which is a potential drawback of this technique. Although we do not use this technique as a primary procedure because of this drawback, it can be added when SAM is still a concern after regular neochordal replacement or leaflet resection. It can be also an effective bailout procedure when postrepair SAM is corrected during the second aortic crossclamping. Adding horizontal folding sutures is much easier and faster than other bailout procedures correcting postrepair SAM, such as replacing the annuloplasty ring, additional neochordal replacement, and leaflet resection.

The caveat of all folding repair techniques is that they are not suitable for the sclerotic leaflet. The leaflet must be pliable enough to be folded without excessive tension. The sclerotic part of the leaflet should be resected. These folding repair techniques we described can be used together with minimal leaflet resection. For example, the chordal foldoplasty technique can be used with triangular resection, in which triangular resection fixes excess leaflet width and removes the sclerotic part of the leaflet, and then chordal foldoplasty corrects the excess leaflet height and prolapse. The folding plus resection repair techniques have been reported, and the simplicity was emphasized as an advantage of those techniques. ${ }^{17,18}$ Although we focused on the "nonresectional" folding approaches in this review article, the folding concept benefits mitral valve repair for degenerative posterior leaflet lesions even when resection is necessary.

No single repair technique fits all mitral valve lesions. Dreyfus and colleagues ${ }^{19}$ reported excellent early and long-term results from their mitral valve repair cases using their "respect when you can, resect when you should" strategy. In their 376 case series, $18 \%$ of patients had nonresectional repair with neochordal replacement or chordal transfer, and others had leaflet resection for excess leaflet tissue with or without chordal or neochordal support. ${ }^{19}$ Having nonresectional folding technique options would save the effort of performing resections and sutures in some patients with excess leaflet tissue. These are useful options that surgeons should have in their skillset.

\section{CONCLUSIONS}

Nonresectional folding repair techniques are simple, reversible, and practical for primary, adjunctive, or bailout techniques in mitral valve repair for degenerative posterior leaflet lesions. Leaflet resection should be the primary technique for sclerotic lesions, but the folding repair techniques can still be used as an additional procedure in such cases. Further investigation is necessary to assess the long-term durability of the folding repair techniques.

\section{Conflict of Interest Statement}

The authors reported no conflicts of interest.

The Journal policy requires editors and reviewers to disclose conflicts of interest and to decline handling or reviewing manuscripts for which they may have a conflict of interest. The editors and reviewers of this article have no conflicts of interest.

The authors thank Dr Nobuhiro Nagata for the illustrations.

\section{References}

1. McGoon DC. Repair of mitral insufficiency due to ruptured chordae tendineae. J Thorac Cardiovasc Surg. 1960;39:357-62.

2. Woo YJ, MacArthur JW Jr. Simplified nonresectional leaflet remodeling mitral valve repair for degenerative mitral regurgitation. J Thorac Cardiovasc Surg. 2012;143:749-53.

3. Tsukui H, Umehara N, Saito H, Saito S, Yamazaki K. Early outcome of folding mitral valve repair technique without resection for mitral valve prolapse in $60 \mathrm{pa}-$ tients. J Thorac Cardiovasc Surg. 2013;145:104-8.

4. Woo YJ, MacArthur JW Jr. Posterior ventricular anchoring neochordal repair of degenerative mitral regurgitation efficiently remodels and repositions posterior leaflet prolapse. Eur J Cardiothorac Surg. 2013;44:485-9.

5. Carpentier A, Adams DH, Filsoufi F. Techniques in type II posterior leaflet prolapse. In: Carpentier A, Adams DH, Filsoufi F, eds. Carpentier's Reconstructive Valve Surgery. Maryland Heights: Saunders; 2010:115-26.

6. McCarthy PM. Mitral leaflet clefts: innocent bystander or covert foe? Heart. 2015;101:1087-8

7. Tabata M, Nishida H, Watanabe S, Uchimuro T, Takanashi S. Interscallop indentation closure as an adjunctive technique in mitral valve repair for degenerative mitral valve disease. Gen Thorac Cardiovasc Surg. 2020;68:233-9.

8. Tabata M, Nakatsuka D, Nishida H, Takanashi S, Hiraiwa N, Kawano Y. A simple nonresectional technique for degenerative mitral regurgitation with a very large posterior leaflet: chordal Foldoplasty. Ann Thorac Surg. 2016;101: e179-81.

9. Tabata M, Kasegawa H, Fukui T, Shimizu A, Sato Y, Takanashi S. Long-term outcomes of artificial chordal placement with tourniquet technique in mitral valve repair: a single-center experience of 700 cases. J Thorac Cardiovasc Surg. 2014;148:2033-8.

10. Fuster GR, Martín E, Paredes F, Mena A, Cánovas S, Gil O, et al. Artificial chordae in the setting of complex mitral valve repair: early outcomes using the folding leaflet technique. Interact Cardiovasc Thorac Surg. 2014;18: 586-95.

11. Calafiore AM, Di Mauro M, Actis-Dato G, Iacò AL, Centofanti P, Forsennati P, et al. Longitudinal plication of the posterior leaflet in myxomatous disease of the mitral valve. Ann Thorac Surg. 2006;81:1909-10.

12. Mihaljevic T, Blackstone EH, Lytle BW. Folding valvuloplasty without leaflet resection: simplified method for mitral valve repair. Ann Thorac Surg. 2006; 82:e46-8.

13. Tabata M, Ghanta RK, Shekar PS, Cohn LH. Early and midterm outcomes of folding valvuloplasty without leaflet resection for myxomatous mitral valve disease. Ann Thorac Surg. 2008;86:1388-90.

14. Gosev I, Yammine M, Leacche M, McGurk S, Ivkovic V, D’Ambra MN, et al. Long term outcomes of posterior leaflet folding valvuloplasty for mitral valve regurgitation. Ann Cardiothorac Surg. 2015;4:428-32. 
15. Schwartz CF, Grossi EA, Ribakove GH, Ursomanno P, Mirabella M, Crooke GA, et al. Ten-year results of folding plasty in mitral valve repair. Ann Thorac Surg. 2010;89:485-8.

16. Abicht TO, Andrei AC, Kruse J, McDonald E, Li Z, McCarthy PM. A simple approach to mitral valve repair: posterior leaflet height adjustment using a partial fold of the free edge. J Thorac Cardiovasc Surg. 2014;148:2780-6.

17. Falk V, Seeburger J, Czesla M, Borger MA, Willige J, Kuntze T, et al. How does the use of polytetrafluoroethylene neochordae for posterior mitral valve prolapse (loop technique) compare with leaflet resection? A prospective randomized trial. J Thorac Cardiovasc Surg. 2008;136:1206.

18. Ben Zekry S, Lang RM, Sugeng L, McCulloch ML, Weinert L, Raman J, et al. Mitral annulus dynamics early after valve repair: preliminary observations of the effect of resectional versus nonresectional approaches. J Am Soc Echocardiogr. 2011;24:1233-42.

19. Dreyfus GD, Dulguerov F, Marcacci C, Haley SR, Gkouma A, Dommerc C, et al. 'Respect when you can, resect when you should': a realistic approach to posterior leaflet mitral valve repair. J Thorac Cardiovasc Surg. 2018;156: 1856-66.e3.

Key Words: minimally invasive surgery, mitral regurgitation, mitral valve repair, robotic surgery 